\title{
Photochemical oxidation of hexahydro-1,3,5-trinitro-1,3,5-triazine (RDX) in aqueous phase
}

\author{
S. M. Celin, M. Pandit \& J. C. Kapoor \\ Centre for Fire, Explosive and Environment Safety, Delhi, India
}

\begin{abstract}
Degradation of RDX in aqueous phase was investigated using photo per oxidation and photo-Fenton oxidation. Destruction and mineralization of RDX were compared for both processes. The oxidation rate was influenced by the amount of $\mathrm{H}_{2} \mathrm{O}_{2}$ and iron salt. In photo per oxidation, $\mathrm{H}_{2} \mathrm{O}_{2}$ at $26.5 \mathrm{mM}$ concentration was found to give the best possible elimination $(97.5 \%$ in 30 minutes). It was found that the photo-Fenton process was more efficient than the photo per oxidation process. In photo-Fenton oxidation, the addition of $3 \mathrm{ml}$ of Fenton's reagent at $3: 1$ ratio $\left(\mathrm{H}_{2} \mathrm{O}_{2}: \mathrm{Fe}^{2+}\right)$ resulted in the destruction of RDX to below detectable level in 30 minutes of irradiation time. The time taken for complete mineralization of RDX in terms of TOC, TN and COD removal was 60 minutes. $\mathrm{NO}_{3}{ }^{-}$and $\mathrm{NO}_{2}^{-}$were the major ionic species produced and trace amounts of $\mathrm{NO}_{2}$ gases were produced. RDX degradation was found to follow first order reaction kinetics.
\end{abstract}

Keywords: RDX, photo-oxidation, direct photolysis, photo peroxidation, photo Fenton oxidation, mineralization.

\section{Introduction}

Hexahydro-1,3,5-trinitro-1,3,5-triazine is a very important secondary explosive, known by various names such as RDX ('Research Development Explosive'/ 'Royal Demolition Explosive' in Anglo Saxon literature), cyclonite, hexogen and $\mathrm{t}_{4}$. RDX has been widely used as an explosive since the early $1900 \mathrm{~s}$ and achieved great importance during 'World War II' as a constituent of many explosive mixtures from which a high power was required. RDX is 1.3 times powerful in explosive properties as compared to tri nitro toluene (TNT) [1]. RDX dissolves 
in water very slowly and also evaporates very slowly from water. Disposal of wastewater from military ammunition plants leads to contamination of water and more so if there are spills and leaks from improper disposal at these plants or at hazardous waste sites. The major toxicological effects observed on exposure to RDX are nausea, irritability, convulsions, unconsciousness and amnesia in humans. The United States Environmental Protection Agency (USEPA) has established the drinking water limit for RDX as $0.030 \mu \mathrm{g} / \mathrm{L}$ [2]. Therefore, it is vital to treat this contaminant before discharge into water bodies.

RDX present in wastewater can be removed by adsorption through granular activated carbon [3], alkaline hydrolysis [4], microbial degradation [5] etc. All these treatment methods do not result in complete destruction as the contaminant is merely transferred from one phase to the other. Treatment methods based on the photo-oxidation principle on the other hand result in complete destruction, as powerful hydroxyl radicals $\left(\mathrm{E}^{\mathrm{o}}=2.8 \mathrm{~V}\right)$ are produced during these processes, which oxidise the contaminant to simpler products such as $\mathrm{CO}_{2}, \mathrm{H}_{2} \mathrm{O}$ and nontoxic molecules [6]. Photo-degradation processes for treating a variety of refractory and toxic organic compounds have been successful; RDX was found to degrade by direct photolysis (Burrows et al. [3]) and photo-oxidation with $\mathrm{H}_{2} \mathrm{O}_{2}$ [7]. However, no information is available on the comparative efficiency of various photo degradation processes in degrading RDX. Hence the present study has been undertaken to carry out extensive observations on photo-degradation of RDX by direct photolysis, photo-peroxidation and photo-Fenton oxidation.

\section{Experimental details}

\subsection{Irradiation experiments}

Studies were conducted in an annular type photochemical reactor of $1 \mathrm{~L}$ capacity. The reactor details were discussed elsewhere [9]. RDX (99.95\% pure) was obtained from the High Energy Materials Research laboratory (HEMRL), Pune. Synthetic solutions of $50 \mathrm{mg} / \mathrm{L}$ RDX were prepared in Milli-Q water and $1000 \mathrm{ml}$ of the RDX solution was taken in the photo-reactor and subjected to UV irradiation emitted from a low and medium pressure $\mathrm{Hg}$ lamp of varying UV intensity viz. 8,15 and $25 \mathrm{~W}$ and 125,250 and $400 \mathrm{~W}$ respectively. The initial $\mathrm{pH}$ of the RDX solution was 6.8. Analytical grade $\mathrm{H}_{2} \mathrm{O}_{2}(30 \% \mathrm{~W} / \mathrm{V})$ and Fenton's reagent (mixture of $\mathrm{H}_{2} \mathrm{O}_{2}$ and $\mathrm{FeSO}_{4} .7 \mathrm{H}_{2} \mathrm{O}$ ) were used as oxidants. The effect of oxidant concentration on photo-degradation of RDX was studied by varying the oxidant dose. $\mathrm{H}_{2} \mathrm{O}_{2}$ concentration varied from 8.8 to $35.3 \mathrm{mM}$. The Fenton reagent, a mixture of $30 \%(\mathrm{~W} / \mathrm{V}) \mathrm{H}_{2} \mathrm{O}_{2}$ and $1 \mathrm{mM} \mathrm{FeSO}_{4} .7 \mathrm{H}_{2} \mathrm{O}(\mathrm{W} / \mathrm{V})$ was used in three different ratios viz., 1:1, 1:3 and 3:1 for optimising the volume ratio. Experiments were carried out thrice for each set of experimental conditions and mean values have been reported.

\subsection{Analytical methods}

Samples were taken at specific time intervals and concentrations of RDX, TOC and COD were determined. The RDX concentration was estimated by HPLC 
(Perkin Elmer Model-1022) with a photo-diode array detector at $235 \mathrm{~nm}$. Acetonitrile and water were used as the mobile phase $(25: 75)$ at a flow rate of 1 $\mathrm{mL} / \mathrm{min}$ and a $\mathrm{C} 8$ column was used as the stationary phase. A TOC analyzer (Elementar High TOC-GmbH, Germany) was used for the determination of total organic carbon (TOC) and total nitrogen (TN) on photo-degradation. The COD content was estimated by oxidation with $\mathrm{K}_{2} \mathrm{Cr}_{2} \mathrm{O}_{7}$. In addition to this, ionic species such as nitrite, nitrate evolved during photo-degradation, were monitored using a HACH spectrophotometer. Total gaseous nitrogen oxides evolved during the experiments were measured by the Indian Standard Procedure [10].

\section{Results and discussion}

\subsection{Direct photolysis (UV) of RDX}

The effect of UV irradiation on removal efficiency of RDX in aqueous phase was studied without oxidants in direct photolytic experiments. Low pressure (8, 15 and $25 \mathrm{~W})$ and medium pressure $(125,250$ and $400 \mathrm{~W}) \mathrm{UV}$ intensities were evaluated for their performance. It was found that exposure to 8,15 , and $25 \mathrm{~W}$ UV lamps resulted in 50, 53 and 69\% destruction of RDX after 30 minutes and exposure to 125,250 and $400 \mathrm{~W}$ medium pressure UV intensities resulted in $73.4,75$, and $77 \%$ destruction of RDX after 30 minutes (Figure 1).

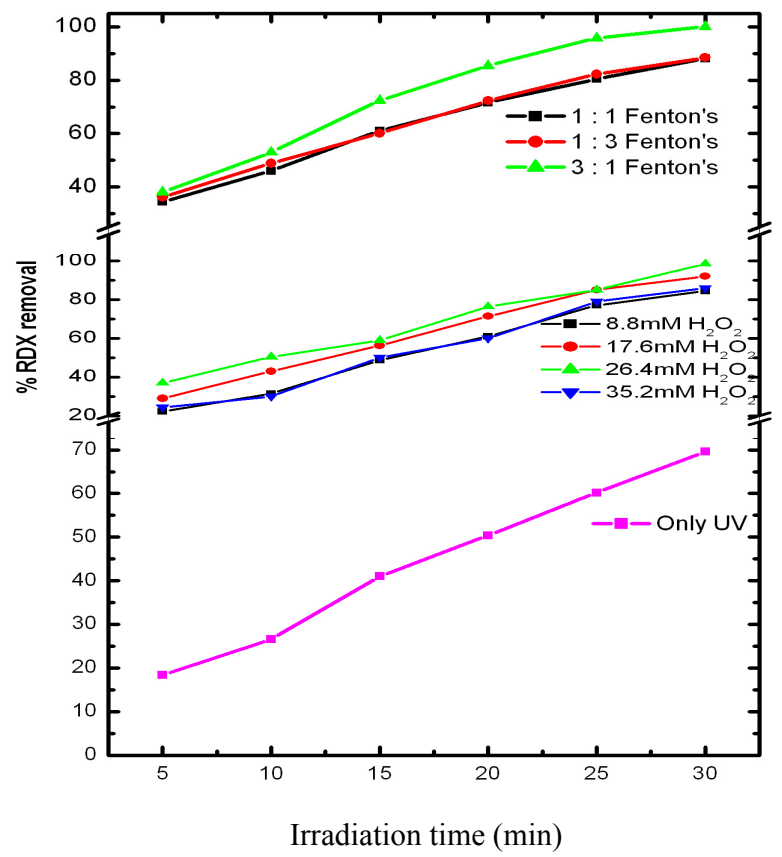

Figure 1: Comparative degradation of RDX by direct photolysis, photo peroxidation and photo-Fenton oxidation. 
In direct photolysis, the organic molecule gets excited on absorption of UV photons. It has been reported that [6] a large number of electronically excited organic molecules could transfer an electron to an acceptor present in its complex environment and form free radical ions These radical ions with subsequent recombination or hydrolysis form radicals, which then react with oxygen to form peroxyl radicals, which on further photolysis get converted to partially oxidized intermediates. In the present study, direct photolysis resulted in a slower rate of oxidation of RDX indicating the capability of UV light in activating the organic molecule into more reactive radical species, which are responsible for the destruction process. In general, however, the direct photolytic experiments are of low efficiency and are less effective compared to procedures involving hydroxyl radical generation [6].

\subsection{Photo peroxidation ( $\mathrm{UV} / \mathrm{H}_{2} \mathrm{O}_{2}$ process)}

Experiments were carried out at different $\mathrm{H}_{2} \mathrm{O}_{2}$ doses in order to optimize the dose of oxidant needed for maximum RDX destruction. The results are graphically illustrated in Figure 1. It is seen from the graph that the rate of destruction of RDX increased with an increase in the initial concentration of $\mathrm{H}_{2} \mathrm{O}_{2}$. The molar ratio of $\mathrm{H}_{2} \mathrm{O}_{2}$ to $\mathrm{RDX}$ was increased with the increase in the $\mathrm{H}_{2} \mathrm{O}_{2}$ dose. More hydroxyl radicals were available to attack the organic compound and the rate of reaction was increased. The optimum dose was found to be $26.5 \mathrm{mM}$, as the maximum RDX degradation (97.5\%) was attained at this dose in 30 minutes of irradiation time. However, after the optimum dose $(26.5$ $\mathrm{mM}$ ), the rate of degradation declined. At a higher dose, $\mathrm{H}_{2} \mathrm{O}_{2}$ acts as a scavenger of highly reactive hydroxyl radicals to form hydro peroxyl radicals, which are much less reactive and do not contribute to oxidative degradation of substrate. Increasing the amount of $\mathrm{H}_{2} \mathrm{O}_{2}$ led to the following competing reaction.

$$
\mathrm{OH}^{\mathrm{o}}+\mathrm{H}_{2} \mathrm{O}_{2} \longrightarrow \mathrm{HO}_{2}{ }^{\mathrm{o}}+\mathrm{H}_{2} \mathrm{O}
$$

Moreover, the effect of UV is lowered at higher concentrations of $\mathrm{H}_{2} \mathrm{O}_{2}$, due to competitive absorption of UV light among the molecules of oxidant and contaminant. Thus, by increasing the $\mathrm{H}_{2} \mathrm{O}_{2}$ concentration above a limiting value, undesirable parallel reactions of $\mathrm{H}_{2} \mathrm{O}_{2}$ were found to occur leading to a decrease in the rate of RDX destruction, in accordance with earlier observations $[11,12]$.

\subsection{Photo-oxidation with Fenton's reagent $\left(\mathrm{UV} / \mathrm{H}_{2} \mathrm{O}_{2}+\mathrm{Fe}^{++}\right)$}

The UV/Fenton system is based on the capture of a photon by an iron salt with its subsequent conversion to ferric ion plus hydroxyl radical [13]. The rate of degradation increased in the presence of ferrous ions, as ferrous ions are catalytic activators in Fenton's reagent and rapid generation of $\mathrm{Fe}^{2+}$ from $\mathrm{Fe}^{3+}$ resulted in more production of $\mathrm{OH}$ radicals.

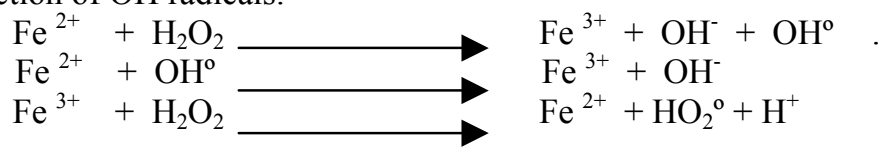




$$
\mathrm{Fe}^{3+}+\mathrm{HO}_{2}{ }^{\mathrm{o}} \longrightarrow \mathrm{Fe}^{2+}+\mathrm{H}^{+}+\mathrm{O}_{2}
$$

The percentage removal of RDX as a function of UV exposure is given in Figure 1. Complete removal of RDX was obtained when $3 \mathrm{ml}$ of Fenton's reagent was used at 3:1 ratio along with $25 \mathrm{~W}$ UV intensity. Fenton oxidation provoked ring cleavage and subsequent elimination of carbon atoms of RDX as $\mathrm{CO}_{2}$.

Photo-Fenton system was found to be superior in its performance compared to photo-peroxidation (Figure 1). In the present study, at higher ratios of $\mathrm{H}_{2} \mathrm{O}_{2} / \mathrm{Fe}^{2+}$ (3:1), all $\mathrm{Fe}^{2+}$ is rapidly converted to $\mathrm{Fe}^{3+}$ according to reaction in equation (2). For the Fenton reaction to continue, $\mathrm{Fe}^{2+}$ must be rapidly regenerated from $\mathrm{Fe}^{3+}$. Two of the possible reaction sequences yielding $\mathrm{Fe}^{2+}$ from $\mathrm{Fe}^{3+}$ are given in equations (4) and (5). The reaction rate of these sequences would be lower if $\mathrm{Fe}^{3+}$ formed condensed species. It was also observed that, higher level of iron salt also result in brown turbidity that interferes in absorption of UV light in contaminant molecules and results in recombination of $\mathrm{OH}^{\circ}$ radicals. Lower iron concentration gave best results (Figure 1). $\mathrm{As}^{2+} e^{2+}$ ions form complexes with other waste effluent components, and downstream removal of iron being difficult, lower concentration of $\mathrm{Fe}^{2+}$ is highly desirable $[11,14,15]$.

\subsection{Mineralization of RDX}

\subsubsection{Reduction in TOC and TN values on photodegradation of RDX}

The rate of TOC and TN removal from the aqueous RDX solutions was monitored. It was found that the total mineralization in terms of TOC removal under photo per oxidation and photo Fenton oxidation systems was 85.1 and $91.6 \%$ respectively and TN removal was 69.1 and $70.7 \%$ respectively. Photooxidation was extremely effective in accelerating the mineralization of RDX. It is most likely that during photo degradation process, the early oxidation reactions of RDX were governed by Fenton $/ \mathrm{H}_{2} \mathrm{O}_{2}$ and its decomposition products, where as the destruction of the oxidation intermediates is achieved by the joint action of UV and oxidant. Among the two-photo oxidative systems evaluated, maximum TOC and TN reduction was achieved with UV/Fenton system (91.6 and 70.7\% respectively in 1.00 hour). The actual mechanism that facilitates the removal of TOC and TN from RDX can be explained by the hydroxyl radical attack on the organic pollutant with the formation of carbon radical intermediates. Subsequently hydroxylated oxidation products are formed that are converted into aldehydes and carboxylic acids and finally via $\mathrm{C}=\mathrm{C}$ bond fragmentation to $\mathrm{CO}_{2}$. The rate of mineralization process is strongly influenced by the number of carbon atoms, structure of the individual compound and the rate of formation of lower molecular species $[17,18]$.

The maximum reduction in TOC level was achieved after 1.00 hour of UV irradiation, whereas the time needed for complete removal of RDX was 30 minutes, i.e., the time needed for the maximum conversion of $\mathrm{RDX}$ to $\mathrm{CO}_{2}, \mathrm{NO}_{2}{ }^{-}$ etc. was more than the time needed for complete destruction of RDX. This confirms that the degradation of RDX to final products occur through formation of lower molecular compounds which in turn are oxidised to $\mathrm{CO}_{2}$. Similar observation was made on degradation of dimethyl-2,2,2-trichloro-1-hydroxy 
ethyl phosphonate and asulum (sodium N-methoxy carbonyl sulfanilamide) wherein the time required for maximum conversion to $\mathrm{CO}_{2}$ was higher [19]. Studies on different organic contaminants have also confirmed the above finding [20-22]. COD removal on Photo-oxidation of RDX was also monitored and it was found that $93 \%$ reduction in COD was obtained in the samples subjected to photo-Fenton oxidation.

\subsection{Estimation of end products produced during photo-oxidation of RDX}

Ionic species and gases formed during the photo-oxidation of $\mathrm{RDX}$ were monitored in the middle (15 minutes) and at the end of the photochemical reaction process (30 minutes and 1.0 hour). The results are given in Table.1. $\mathrm{NO}_{3}{ }^{-}$and $\mathrm{NO}_{2}{ }^{-}$were the major ionic species formed and trace amounts of $\mathrm{NO}_{2}$ gas also evolved. It is important to note that the nitrite ion concentration was more at 30 minutes and at the end of the photochemical reaction, i.e. at 60 minutes, the concentration of nitrite ion reduced almost to zero. Whereas the nitrate ion concentration was very less at 30 minutes and at the end of the photooxidation it increased. This decrease in concentration of nitrite ion and increase in concentration of nitrate ion at the end of the process is due to the oxidation of nitrite to nitrate. The above observation was confirmed by measuring the $\mathrm{pH}$ of the treated solution. The $\mathrm{pH}$ of the reaction media decreased from neutral to acidic range. This is because the nitrogen contained in the RDX molecule could partially lead to nitric acid formation, which is proved by the presence of nitrate ions as discussed above. Similar study on $\mathrm{TiO}_{2}$ photo catalytic degradation of TNT reported the oxidation of TNT to initially nitrite and finally to nitrate [23].

Table 1: $\quad$ End-products formed on photo-oxidation of RDX.

\begin{tabular}{|c|c|c|}
\hline Ionic Species & $\mathrm{UV}+\mathrm{H}_{2} \mathrm{O}_{2}$ & $\mathrm{UV}+$ Fenton \\
\hline 30 minutes & & \\
$\mathrm{NO}_{2}^{-}-\mathrm{N}(\mathrm{mg} / \mathrm{L})$ & 13.81 & 13.5 \\
$\mathrm{NO}_{3}^{-}-\mathrm{N}(\mathrm{mg} / \mathrm{L})$ & 3.92 & 4.80 \\
\hline 60 minutes & & \\
$\mathrm{NO}_{2}^{-}-\mathrm{N}(\mathrm{mg} / \mathrm{L})$ & 3.30 & 2.80 \\
$\mathrm{NO}_{3}^{-}-\mathrm{N}(\mathrm{mg} / \mathrm{L})$ & 14.00 & 14.20 \\
Gaseous NOx (mg/L) & 1.0 & 1.2 \\
\hline Total Nitrogen & 18.3 & 18.2 \\
$(\mathrm{mg} / \mathrm{L})$ & & \\
\hline
\end{tabular}

\subsection{RDX destruction-reaction kinetics}

Photo-oxidation of RDX may be represented as follows

$$
\mathrm{RDX} \stackrel{\mathrm{UV}+\text { Oxidant }}{\longrightarrow} \text { Products } \ldots
$$

A linear plot of $\left\{-\ln \left(\mathrm{C}_{\mathrm{t}} / \mathrm{C}_{0}\right)\right\}$ (Figure 2.) shows that the rate of degradation of $\mathrm{RDX}$ is a pseudo first order reaction assuming that the degradation is 
independent of hydroxyl radical concentration. The average over all rate constants under the $\mathrm{UV} / \mathrm{H}_{2} \mathrm{O}_{2}$ and $\mathrm{UV} /$ Fenton systems were found to be 0.12 and $0.15 \mathrm{~min}^{-1}$ respectively. Half-life values for both the systems were calculated to be 5.7 and 4.6 minutes respectively.

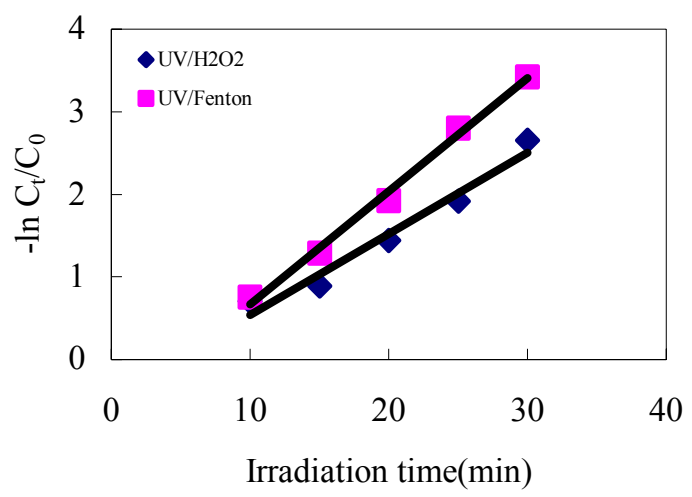

Figure 2: $\quad$ First order reaction kinetics of RDX.

\section{Conclusion}

Photo-oxidation with $\mathrm{H}_{2} \mathrm{O}_{2}$ /Fenton's reagent is highly efficient for destruction and mineralization of RDX. The oxidation rates were influenced by the amount of $\mathrm{H}_{2} \mathrm{O}_{2}$ and iron salt. In photo peroxidation, $\mathrm{H}_{2} \mathrm{O}_{2}$ at $26.5 \mathrm{mM}$ concentration was found to give the best possible elimination. In photo-Fenton oxidation, addition of $3 \mathrm{~mL}$ of Fenton's reagent at $3: 1$ ratio $\left(\mathrm{H}_{2} \mathrm{O}_{2}: \mathrm{Fe}^{2+}\right)$ resulted in destruction of RDX to below detectable level. Direct photolysis resulted in slower rate of degradation. On comparison of two photo-oxidative processes, it was found that photo-Fenton process is more efficient than photo peroxidation. In 30 minutes of UV irradiation, complete destruction (below detectable level) of RDX occurred in the photo-Fenton process. In $\mathrm{UV} / \mathrm{H}_{2} \mathrm{O}_{2}$ process, $97.5 \%$ destruction of $\mathrm{RDX}$ was found to occur. Prolonged exposure (60 minutes) to UV irradiation resulted in complete mineralization of RDX to simpler products. In the photo-Fenton process, reduction in TOC, TN and COD contents were found to be $91.6 \%$, $70.7 \%$ and $93 \%$ respectively. In the photo peroxidation process, reduction in TOC, TN and COD contents were found to be $85.1 \%, 69.1 \%$ and $88.7 \%$ respectively. $\mathrm{NO}^{2-}$ and $\mathrm{NO}^{3-}$ were the major ionic species produced and trace amounts of NOx gases were also produced. RDX degradation was found to follow first order reaction kinetics.

\section{References}

[1] R.M. Bricka, W. Sharp, Treatment of ground water contaminated with low levels of military munitions. Technical Report for the US army Corps of Engineers, 1992. 
[2] U.S. Environmental Protection Agency, Health Advisory for RDX, Washington, D.C., Environmental Protection Agency, Criteria and Standards Division, Office of Drinking Water. 1988c.

[3] E.P. Burrows, D.H. Rosenblatt, W.R Mitchell, D.L. Parmer, Organic Explosives and related compounds; Environmental and Health Consideration. Biomedical Research and Development Laboratory, Fort Detrick, Maryland, USA, 1989, TR-8901.

[4] H.M. Heilmann, U. Weismann, M.K. Stenstorm, Kinetics of the alkaline hydrolysis of high explosives RDX and HMX in aqueous solution and adsorbed to activated carbon. Env. Sci. Tech., 5 (1996) 1485-1492.

[5] H.C. Sikka, S. Banerjee, E.J. Pack, H.T. Appleton, Environmental fate of RDX and TNT. Technical report No: 81-538, U.S. Army Medical research and Development Command, Fredrick, MD.1980.

[6] O. Legrini, E. Oliveros, A.M. Braun, Photochemical processes for water treatment. Chem. Rev. 93(2) 671-698.

[7] C.E. Fleming, M.R. Bricka R.S. Bailey, Ultraviolet/Chemical oxidation Treatment of RDX contaminated waters. Technical Report: EL-95-7, U.S. Army Corps of Engineers, Vicksburg, MS. 1995.

[8] Heinrich, A Photocatalytic Treatment of RDX Wastewater with NanoSized Titanium Dioxide (5 pp) Environmental Science and Pollution Research 13 (5), (2006), 328-332.

[9] M.S. Celin, M. Pandit, J.C. Kapoor, R.K. Sharma, Studies on photo degradation of 2,4-dinitro toluene in aqueous phase, Chemosphere, 53 (2003) 63-69.

[10] Indian Standard IS: 5782 (Part-II) 1969.

[11] Y.M. Ghaly, G. Hartel, R. Mayer, R. Hasender, Photochemical oxidation of p-chlorophenol by UV/ $\mathrm{H}_{2} \mathrm{O}_{2}$ and $\mathrm{UV} /$ Fenton process. A comparative study, Waste Management, 212001 41-47.

[12] A.K. De, B. Chaudhuri, S. Bhattacharjee, K.B. Dutta, Estimation of OH• radical reaction rate constants for phenol using $\mathrm{UV} / \mathrm{H}_{2} \mathrm{O}_{2}$ photo oxidation. J. Haz. Mat., 64 (1999) 91-104.

[13] C. Walling, Fenton's reagent revisited, Accts. Chem. Res., (1975) 1-12p.

[14] A.A. Bham, P.R. Chambers, Degradation of high molecular weight chlorinated aromatics and aliphatics in bleach plant effluent by Fenton's reagent. Adv. Env. Research, 1(2) (1997) 135-143.

[15] W.W. Powell, D.l. Michelsen, D.G. Boardman, M.A. Dietrich, M.R. Woodby, Removal of colour and TOC from segregated dye discharges using $\mathrm{O} 3$ and Fenton's reagent. In: Chemical Oxidation - technology for the nineties. (Ed. Eckenfelder, W.W., Bowers, R.A and Roth, A.J) Technomic Publ. Co., Basel, 1992, 206p.

[16] Masschelein, W.J, 1992, Unit Processes in drinking water treatment, Marcel Decker Inc. New York, P 149.

[17] M.C. Gonzalez, A.M. Braun, Vacuum UV photolysis of aqueous solutions of nitrate; effect of organic matter: 1 Phenol. J. Photochem. Photobiol. A: Chem. 93 (1) (1996) 7-19. 
[18] M.I. Stefan, A.R. Hoy, J.R. Bolton, Kinetics and mechanism of degradation and mineralization of acetone in dilute aqueous solution sensitised by the UV photolysis of $\mathrm{H}_{2} \mathrm{O}_{2}$. Environ. Sci. Technol. 30 (7) (1996) 2382-2390.

[19] K. Tanaka, K. Abe, C.Y. Sheng, T. Hisanaga, Photocatalytic wastewater treatment combined with ozone pretreatment, Env. Sci. Tech. 26 (1992) 2534-2536.

[20] W.H. Glaze, J.W. Kang, D.H. Chapin, The chemistry of waste water treatment processes involving Ozone, Hydrogen peroxide and UV radiation, Ozone. Sci. Eng. 9 (1987) 335-352.

[21] E. Pelzzetti, V. Maurino, C. Minero, V. Carlin, M.L. Tosato, E. Pramauro, O. Zeribinati, Photocatalytic degradation of atrazine and other S-triazine herbicides. Environ. Sci. Technol. 24 (10) (1990) 1559-1565.

[22] E. Oliveros, O. Legrini, M. Hohl, J. Muller, M.A. Braun, Industrial wastewater treatment: Large scale development of a light enhanced Fenton reaction. Chem. Eng. and Proc. 36 (1997) 397-405.

[23] D.C. Schmelling, K.A. Gray, P.V. Kamat, Role of Reduction in the Photocatalytic Degradation of TNT. Env. Sci. Tech. 30(8) 1996) 25472555 . 